Pesquisa e Reflexão em Educação Básica

\title{
Os jovens e o futuro: diferentes percepções sobre as camadas médias e os moradores de favelas
}

Raquel Brum Fernandes ${ }^{1}$

\begin{abstract}
Resumo:
A juventude é frequentemente compreendida, tanto no senso comum como em textos acadêmicos, como um período de conflitos, crises e decisões. A partir de tal percepção, os estudos sobre grupos jovens das camadas médias cariocas têm já há alguns anos indicado que os processos de construção das identidades ocorrem de forma fluida e desprendida, alternando momentos e combinando atividades, sem seguir os padrões de comportamento desempenhados por gerações anteriores. Em relação aos jovens moradores de favelas, entretanto, são constantemente destacadas as vulnerabilidades de suas trajetórias, determinadas pelas diversas contingências sociais em que estão inseridos, sem que haja margem para a autonomia individual. O objetivo desse trabalho é destrinchar essas diferentes perspectivas em relação aos jovens, a partir de entrevistas feitas com moradores de um conjunto de favelas da zona norte do Rio de Janeiro. Procurarei evidenciar que, dentro de seus campos de possibilidades, esses jovens também constroem trajetórias múltiplas e diversas.
\end{abstract}

\section{Palavras-chave:}

Juventude. Futuro. Favelas.

\section{Young people and the future: different perceptions of the middle classes and slum dwellers}

\begin{abstract}
Youth is often understood both in common sense and academic writing as a period of conflict, crisis and different decisions. Studies on young groups from Rio's middle classes have for some years now indicated that the construction of identities occurs in a fluid and detached way, with alternated moments and combined activities, not following patterns of behavior performed by previous generations. In relation to young slums residents, however, the vulnerabilities of their trajectories determined by the various social contingencies in which they are inserted are constantly highlighted, with no scope for individual autonomy. The aim of this work is to unravel these different perspectives in relation to young people, based on interviews with residents of a set of slums in the north of Rio de Janeiro. I will try to evince that within their fields of possibilities, these young people also develop multiple and diverse trajectories.
\end{abstract}

Keywords: Youth. Future. Slums.

\footnotetext{
1 Doutora em Ciências Sociais. Professora da UFF em Campos dos Goytacazes. E-mail: raquel_bfs@hotmail.com. ORCID iD: http://orcid.org/0000-0002-4176-3579.
} 


\title{
Los jóvenes y el futuro: diferentes percepciones de las clases medias y los habitantes de los barrios marginales
}

\begin{abstract}
Resumen: La juventud a menudo se entiende tanto en el sentido común como en textos académicos como un período de conflicto, crisis y decisión. Los estudios sobre grupos jóvenes de la clase media del Río indican que desde hace algunos años los procesos de construcción de identidades ocurren de manera fluida y suelta, cambiando momentos y combinando actividades, sin seguir los patrones de comportamiento de generaciones anteriores. En relación a los jóvenes habitantes de los barrios marginales, sin embargo, las vulnerabilidades de sus sectores están determinadas por las diversas contingencias sociales en las que se destacan constantemente, sin margen de autonomía individual. El propósito de este trabajo es dar a conocer estas diferentes perspectivas sobre los jóvenes, a través de entrevistas con residentes de un conjunto de barrios marginales del norte de Río de Janeiro. Intentaré demostrar que, dentro de sus campos de posibilidades, estos jóvenes también construyen múltiples y diversas trayectorias.
\end{abstract}

Palabras-clave: Juventud. Futuro. Barrios Marginales.

\section{Introdução}

\begin{abstract}
Enquanto as gerações mais velhas orientam a sua vida por caminhos e valores de segurança e rotina, os jovens escolhem, muitas vezes, as rotas da ruptura, do desvio. Podemos dizer que as velhas gerações tendem a jogar com os valores de forma conservadora. Recorrendo à metáfora do xadrez, dir-se-ia que movimentam os valores no tabuleiro da vida, com passividade e prudência, seguindo a tática do 'bispo mau'. Esta tática consiste em colocar o maior número de peões em casas da cor das diagonais por onde os bispos circulam, na suposição de que, desse modo, os peões se defendam mais facilmente. Em contrapartida, os jovens tentam assegurar objetivos de mobilidade e de ataque, mesmo pondo em risco a sobrevivência do bispo. (PAIS, 2006, p. 10-11).
\end{abstract}

A juventude é frequentemente compreendida como um período de conflitos e questionamentos, visto que por estarem ainda se adaptando às regras do mundo "adulto", os jovens tenderiam a desafiá-las. De acordo com Hermano Vianna, mesmo nas Ciências Sociais os primeiros estudos dedicados ao tema convergiram na definição da juventude como "[...] um estado de rebeldia, revolta, transitoriedade, turbulência, agitação, tensão, mal-estar, possibilidade de ruptura, crise psicológica, conflito (em outros textos encontramos as palavras instabilidade, ambigüidade, liminaridade, flexibilidade, inquietude)" (VIANNA, 1997, p. 12). Segundo o autor, a juventude seria vista como em oposição à ordem social vigente, transformadora e revolucionária. Todas essas posturas de "revolta", "crise" e "conflito" seriam peculiares deste momento de transição para a maturidade. Dessa forma, os jovens seriam ainda incompletos, transformando-se naquilo que efetivamente viriam a ser enquanto indivíduos (adultos).

Diversos estudos mais defendem, entretanto, que no contexto moderno a juventude teria deixado de ser apenas um estado de transição, e teria se tornado um universo em si mesmo. Alguns autores destacam como a condição "jovem" passou a caracterizar não apenas uma faixa etária, mas um estilo de vida. "Parecer jovem" e "sentir-se jovem" são desejos intensamente valorizados nos mais diversos segmentos da sociedade por indivíduos de diferentes idades (VELHO, 1990).

O objetivo deste trabalho é apresentar como jovens de camadas médias e moradores de favelas são compreendidos a partir de critérios distintos: os primeiros com o foco em suas escolhas e identidades, os segundos de forma determinista e estigmatizada. Para isso, farei referência a entrevistas realizadas com jovens moradores de um conjunto de favelas da zona norte do Rio de Janeiro, nas quais questionei sobre suas perspectivas para o futuro e sua participação em "projetos sociais" que ofertavam atividades para a juventude da região. 


\section{Jovens de camadas médias}

Os estudos sobre grupos jovens das camadas médias cariocas têm já há alguns anos indicado que os processos de construção das identidades não ocorrem de forma rígida ou definitiva (ALMEIDA; EUGÊNIO, 2006; ALMEIDA; TRACY, 2003; ROCHA; ALMEIDA; EUGÊNIO, 2006; VELHO, 1987, 1990). Embora a juventude seja valorizada como período onde as questões identitárias são mais explicitamente negociadas, isso não significa que as preferências, interesses e perspectivas constituídos nessa fase permanecerão inalterados ao longo da vida. Na verdade, o que pode ser percebido é que já durante os anos que configuram a chamada "juventude" as identidades são construídas de forma fluida e desprendida. De acordo com Cláudia Rezende:

Desvendar a diversidade de identidades jovens de segmentos médios cariocas é um trabalho lento, difícil. O que em um momento se apresenta como identidade pode deixar de sê-lo em um instante seguinte. Estudar jovens de 15, 16 anos se traduz em analisar uma fotografia que capta uma fração de tempo. (REZENDE, 1990, p. 22).

Maria Isabel Mendes de Almeida e Kátia Tracy (2003) dedicaram-se a analisar as configurações dessas "fotografias", desses instantes captados que constituem as identidades jovens, através das interações desenvolvidas no contexto da night carioca. Elas defendem que, ao observar as práticas que compõem a rotina de lazer nas noites jovens, poderiam ser percebidos os códigos e condutas que caracterizam seus modos de vida de forma geral. A principal característica da night seria a mobilidade. A rede de sociabilidades desenvolvidas nela não dependeria, segundo as autoras, de espaços pré-determinados ou específicos como boates e clubs. Pelo contrário, os momentos de lazer poderiam se desenrolar nas portas ou calçadas dos locais dos eventos (muitas vezes terminando por ali mesmo), em postos de gasolina, lanchonetes e até mesmo dentro dos carros. Na maioria das vezes, o decorrer da noite perpassava por todos estes lugares, para fazer a "social", sempre à procura do lugar mais interessante. E seria justamente essa transitoriedade, tanto de espaços quanto de grupos de pessoas encontradas pelo caminho, de práticas de "zoação" e "azaração" que comporia a night propriamente dita. De acordo com as autoras:

Se pairam dúvidas quanto aos pontos passíveis de serem ocupados a partir da dinâmica da diversão noturna, os jovens são unânimes em relação ao que faz a 'boa night': lugares 'maneiros' com gente bonita. Assim 'o lugar legal é você estar com seus amigos que você gosta, no limite, sem fazer merda. Se você está com seus amigos que você gosta, qualquer lugar é um lugar legal'. A mobilidade tornou-se, assim, a principal característica da noite carioca, transformando o lazer noturno em uma experiência transespacial, pois a lógica da 'social' é deslocalizada. (ALMEIDA; TRACY, 2003, p. 64).

Essa mobilidade juvenil poderia ser observada não apenas nas configurações do lazer noturno, mas em diversos outros momentos da vida social. A constituição de relacionamentos afetivos/sensuais/ sexuais, por exemplo, adquire características extremamente situacionistas sob a forma do "ficar". As autoras destacam como essas interações, configuradas normalmente apenas por olhares direcionados e beijos (com algum diálogo ou não), não dependem de história ou projeções de futuro entre os envolvidos. Seriam momentos fugazes, com fins em si mesmo, embora possam ser considerados muitas vezes o primeiro passo para um relacionamento mais duradouro. Segundo Fernanda Eugênio (2006), essas expectativas em torno de relações de compromisso mútuo estão diminuindo e a abordagem entre homens e mulheres tem sido facilitada.

Também no que diz respeito ao campo do trabalho, pode-se afirmar que as trajetórias jovens têm apresentado percursos descontínuos, em detrimento da antiga noção de carreira formal, concentrada em uma mesma área e/ou empresa. Maria Isabel Mendes de Almeida e José Machado Pais (2012) 
defendem que as perspectivas profissionais da juventude são marcadas pela criatividade, através da reinvenção e (re) significação de categorias que tradicionalmente configuram o mundo do trabalho. A própria noção de autoria, por exemplo, tão cara ao universo profissional especialmente artístico, passaria por transformações abruptas nos processos contemporâneos de produção (ALMEIDA, 2012). As atuais conjunturas econômicas, com ampliação da concorrência em várias áreas do mercado, aliadas à multiplicação das formas de comunicação, propaganda e marketing proporcionariam o surgimento de novas formas de empreendedorismo criativo. Dentro desse contexto se ampliariam as produções em grupo, a ocupação de novos espaços e tempos como lócus de trabalho e a cooperação entre concorrentes, ou seja, seriam empregadas diversas alternativas a fim de promover a sobrevivência dos empreendimentos. Fernanda Eugênio (2012) também observou a importância da criatividade nas configurações juvenis de trabalho. Segundo a autora:

Do mesmo modo que os espaços reversíveis, capazes de se transformarem em outros pelo uso, também o funcionamento profissional se dá por sucessivas 'migrações' ou acúmulos de habilidades e ocupações exercidas em simultâneo: é frequente a operação do 'virar', em vez da lógica da carreira progressiva que forma o especialista. Afetando ao mesmo tempo a organização da vida profissional e o entendimento do que seja uma boa formação, percebemos que a lógica instalativa ou da ocupação temporária que 'vira' outra e outra e outra, em regime de reversibilidade ou de simultaneidade, se utiliza dos modos de produzir não apenas os espaços, mas também o próprio entendimento de si como agente criador. (EUGÊNIO, 2012, p. 229-230).

Dessa forma, as trajetórias profissionais não seriam mais construídas de forma exclusivista, com dedicação total a uma determinada área de interesse. Muitos jovens desenvolveriam carreiras paralelas sobre temáticas distintas ou assumiriam trabalhos temporários ou freelancer enquanto se preparam para mudar de área profissional. Na verdade, muitas vezes os projetos temporários constituiriam a totalidade das perspectivas de trabalho dos jovens, tanto pela escassez de cargos estáveis e duradouros no mercado, quanto pela própria preferência de alguns profissionais por horários e formatos mais flexíveis de trabalho. Isso não significa que os jovens não possuam projetos de carreira mais ou menos direcionados e áreas de interesse definidas, nem que não busquem algum tipo de estabilidade econômica. As formas de fazer isso é que se tornaram mais fluidas, dotadas de diversas possibilidades de escolha e abertas a mudanças no meio do percurso. "É preciso, pois, que haja um esboço para dar direção à ação. Mas é preciso também que ele seja aberto a acolher imprevistos e acidentes, fazendo deles a matéria com a qual trabalhar e inventar, cultivando habilidades em ato" (EUGÊNIO, 2012, p. 236). É importante destacar que as novas configurações do trabalho são devedoras do desenvolvimento tecnológico dos últimos anos. Aparelhos e softwares que acumulam cada vez mais funções têm permitido encurtar distâncias e otimizar o tempo. Através de ferramentas como Whatsapp e o Skype, por exemplo, pessoas em lados opostos do mundo podem trabalhar juntas em um mesmo projeto ou empresa. Além disso, sabemos que os jovens são usualmente identificados como grupo social que mais se adapta às inovações tecnológicas. Por terem nascido em um mundo que já era digital, teriam facilidade em manusear equipamentos e, principalmente, dominar os códigos do mundo virtual.

A partir da reflexão desenvolvida acima, pode-se perceber que os jovens de classes médias transitam em diferentes profissões, maneiras de se relacionar, opções e formatos de lazer, entre muitos outros aspectos da vida em sociedade. A todo o momento estão reconfigurando suas formas de identificação. E é justamente essa gama de possibilidades, esse repertório de lugares em que se pode estar, essas inúmeras áreas e formas de se trabalhar, de se relacionar, de se divertir, que possibilitam a transição, a descontinuidade, o "virar-se" uma coisa e depois voltar atrás e "virar" outra. As opções alimentam a transitoriedade, que por sua vez permite que elas sejam vistas. Nesse processo recíproco, a cada escolha, a cada descontinuidade, novas negociações de diferenciação/pertencimento vão sendo feitas e com elas novas formas de identificação são definidas. O conjunto das múltiplas identificações 
que coexistem em um determinado momento da vida de um jovem configura, naquele momento, a sua identidade. Gilberto Velho afirmou que: "[...] a participação em diferentes mundos (ver BECKER, 1982) com múltiplas experiências heterogêneas significativas acusa a percepção de uma singularidade individual" (1990, p. 2). Dessa forma, fugazes como os momentos captados por uma fotografia, as identidades vão se acumulando nos álbuns que são as trajetórias individuais.

\section{Jovens moradores de favelas}

Seja por características psicológicas normalmente associadas à faixa etária, pela pressão exercida pelo meio no qual vivem, por predisposições individuais ou até pela combinação de todos esses fatores, os jovens das comunidades pobres são constantemente destacados como principal grupo a ser seduzido pelos atrativos do tráfico organizado. Essa visão aparece recorrentemente no discurso de gestores de programas e projetos, moradores das comunidades e outros representantes do governo (FERNANDES, 2013). Mesmo aqueles que não se encontram incluídos em nenhuma prática criminosa, por serem jovens estariam sempre em "risco" de se envolverem (ou serem envolvidos) em alguma situação reprobatória. De acordo com o trecho abaixo:

Em nossa sociedade, a categoria 'jovem' tornou-se um 'problema social'. A juventude, principalmente a adolescência, é concebida como momento de crise, irresponsabilidade, rebeldia. O jovem é representado como potencialmente perigoso e, como aponta Abramo (1997), nas matérias veiculadas nos meios de comunicação, costuma ser associado a outros 'problemas sociais', como a violência, a exploração sexual, o uso de drogas e a gravidez precoce. (PICCOLO, 2010, p. 110).

Essas concepções referentes à juventude como "problema social" tendem a ser intensificadas quando se referem às camadas populares. As peculiaridades da vida social em territórios de pobreza, especialmente aqueles "governados" ou influenciados por organizações de traficantes, funcionariam como agravante nesse contexto. Mais uma vez, segundo Fernanda Piccolo: "A classificação dos jovens como em 'situação de risco' apoia-se em diversos índices, como local de moradia, a falta de escolaridade e a percepção da ambígua relação de medo e fascínio com os membros do tráfico" (2010, p. 114). Já se tornou conhecida a noção de que a vida nas favelas dominadas por traficantes apresenta aos jovens um universo de desfechos trágicos e ao mesmo tempo oportunidades de status e ascensão social. Segundo Sílvia Ramos, a partir de entrevistas e grupos focais realizados com moradores de diferentes favelas da cidade:

As relações entre, de um lado, 'conseguir meninas', 'ser assediado por garotas bonitas', 'ser olhado, reconhecido, desejado' e, de outro, 'usar armas', 'ser do tráfico', 'virar bandido' foram mencionadas sem exceção por jovens de projeto, rapazes ou moças, traficantes e lideranças. Mesmo quando este ponto não estava em nosso roteiro prévio. (RAMOS, 2011, p. 50).

O painel explicativo frequentemente acionado na construção da vulnerabilidade dos jovens moradores e favelas é composto por noções de que possuem famílias desestruturadas, que não proporcionariam o suporte e educação necessários, além de conviverem com uma oferta de oportunidades ilícitas de renda e destaque social. Destaca-se também a relação conflituosa que esses jovens desenvolvem com a escola, muitas vezes evadindo e não completando a formação necessária para uma inserção mais qualificada no mercado de trabalho. É a partir desse contexto de vulnerabilidade que são explicadas muitas das "causas" do envolvimento de juventudes pobres com o tráfico de drogas (PICCOLO, 2010; RAMOS, 2011; SENTO-SÉ; COELHO, 2011). Dessa forma, já há algumas décadas, diversas iniciativas têm surgido com o objetivo de orientar e auxiliar esses jovens, buscando evitar o determinismo das 
vulnerabilidades nas quais estariam inseridos. Entre políticas públicas, programas de governo, ações de empresas privadas e empreitadas comunitárias (coletivas ou individuais), são chamadas de "projetos sociais" as diferentes organizações que buscam promover transformações sociais em relação às conjunturas socioeconômicas da vida nas favelas. De acordo com Regina Novaes:

Para aqueles que têm acesso, os projetos podem contribuir para a supressão de certas marcas de exclusão pelo aumento da escolaridade, da capacitação profissional, da consciência étnica, de gênero, de pertencimento local comunitário. Os projetos sociais tornaram-se pontes para um determinado tipo de inclusão social de jovens moradores de certas áreas marcadas pela pobreza e pela violência das cidades. Com eles, uma parcela dos jovens pode inventar novas maneiras de sociabilidade e integração societária que resultem em determinadas modalidades de inclusão. (NOVAES, 2006, p. 113-114).

Embora muitos "projetos sociais" defendam noções relativas à afirmação étnica e territorial, além de denunciarem a negação de cidadania aos moradores de favelas, é o tema da inclusão social pelo do trabalho que motiva grande parte dessas iniciativas (NOVAES, 2006). Como consequência, a oferta de atividades artísticas, esportivas e, principalmente, de reforço escolar e cursos profissionalizantes, predomina entre as ações dos "projetos". Ao procurarem auxiliar os jovens na construção de trajetórias consideradas "saudáveis", essas organizações fazem referência a um modelo tradicional biográfico, que segundo Adalberto Cardoso consistiria em:

[...] uma concepção de trajetória de vida típica do capitalismo organizado, ou do Estado de Bem-Estar Social, segundo a qual a entrada na fase adulta estava associada à obtenção de um emprego, em uma seqüência de eventos que conectava, de forma mais ou menos estruturada, nascimento $\rightarrow$ socialização em família $\rightarrow$ entrada na escola $\rightarrow$ entrada no mercado de trabalho, essa última coincidindo, no mais das vezes, com a constituição, pelo jovem, de sua própria família. (CARDOSO, 2008, p. 581-582).

Assim, o emprego em posições formais de trabalho é compreendido em oposição direta ao envolvimento com o tráfico, já que este seria fomentado pela desocupação da juventude (CARDOSO, 2008). Embora a inserção dos jovens no mercado profissional seja o principal objetivo de muitos "projetos sociais", o processo de "ocupar" o tempo dos jovens através de atividades artísticas, esportivas ou durante o período dos cursos de qualificação já traria benefícios em si, visto que a simples convivência em espaços "saudáveis" reduziria a exposição dos jovens aos atrativos do crime organizado (FERNANDES, 2013; PICCOLO, 2010).

\section{Os "projetos sociais" e os projetos de futuro}

Durante a realização da pesquisa que originou minha tese de doutorado, defendida em 2015 no Programa de Pós-Graduação em Ciências Sociais da UERJ, realizei entrevistas com jovens moradores do grupo de favelas do Complexo do Andaraí/Grajaú1, localizado na zona norte do Rio de Janeiro. O objetivo era compreender as percepções da comunidade sobre a juventude local, além de observar as relações dos jovens com os "projetos sociais" que se multiplicavam na região, notando se a participação nestas iniciativas se articulava com seus projetos de futuro. Entrevistei, entre 2012 e 2015, dez jovens de idades entre 16 e 24 anos, seis mulheres e quatro homens, oito negros e dois (um homem e uma mulher) brancos. 
Entre os jovens entrevistados, todos, com exceção de dois, afirmaram que gostariam de participar de ao menos uma atividade ofertada por "projetos sociais". É importante destacar que em nenhum momento foi necessário que eu explicasse a que tipo de iniciativas eu me referia quando utilizava a expressão "projeto social". Todos os jovens com quem conversei demonstraram uma compreensão imediata da expressão, referindo-se à oferta de atividades esportivas, artísticas, organização de passeios e eventos e, principalmente, cursos para formação profissional. Na verdade, os depoimentos revelaram quase uma indistinção entre as noções de "projeto social" e curso. Uma de minhas entrevistadas, Yasmim, fez o seguinte comentário ao falar sobre a existência de projetos na região do Andaraí: "Ah, alguns projetos... ou cursos... que é tudo a mesma coisa". Na mesma entrevista, ao responder sobre seus objetivos ao participar de um projeto de dança, Yasmim afirmou:

Eu espero... Sei lá, eu espero um dia a gente fazer sucesso.

[...] Eu quero ser bailarina sim.

[...] Eu quero até lá arrumar um trabalho de jovem aprendiz e com esse dinheiro que eu pegar, pagar minha faculdade.

Faculdade de quê??

Eu não sei explicar, eu sei que eu tenho que fazer faculdade de Educação Física para eu pegar um papel, sei lá, para mim entrar em Dança. (Yasmim, 16 anos, moradora do Morro do Andaraí).

Outra entrevistada, Kamila também demonstrava objetivos profissionais ao participar do projeto, mas destaca possuir uma segunda opção:

No momento, eu tenho dois sonhos. Um é de ser dançarina profissional independente do meu corpo ou meu peso. Meu segundo sonho é ser uma administradora. Daqui a dez anos eu me vejo com meu grupo de dança fazendo sucesso. [...] Me vejo me apresentando em grandes lugares importantes, como teatros, festival de danças, eventos, até televisão se for possível. Me vejo uma dançarina conhecida. Sobre a parte da administração eu nunca parei pra me imaginar tanto, eu gosto, mas não é o que fico pensando o tempo todo. Administração será minha segunda opção. Se até eu terminar meus estudos, eu vou ter uma visão de que vai dar certo se eu continuar. Não tem faculdade para ser dançarina, só coreógrafa, pelo menos na minha pesquisa mostra isso. Para seguir como profissão se isso não dá certo, no momento eu penso em fazer administração, mas mesmo assim continuarei dançando. (Kamila, 16 anos, moradora do Morro do Andaraí).

Já Natânia, embora afirme gostar de participar do projeto de dança, não o relaciona a fins ou formação profissional. Ela deseja construir uma carreira em outra área:

Eu me vejo educando crianças para um futuro melhor. Quero fazer pedagogia e para isso já estou estudando no curso normal do Colégio Júlia Kubistchek. (Natânia, 16 anos, moradora do Morro do Andaraí).

Outro jovem entrevistado, Jefferson, não participava naquele momento de nenhum projeto. Entretanto, já havia concluído um curso de informática oferecido nas proximidades do Andaraí, e explicou que, como gostava muito de desenhar, gostaria que existisse algum curso profissionalizante nesta área. Segundo ele:

Eu gosto muito de desenhar, eu queria seguir alguma profissão nessa área. [...] Eu gostaria que aqui tivessem mais cursos... (Quais?) De desenhista cartunista, eu queria muito fazer esse curso. (Jefferson, 19 anos, morador do Morro do Andaraí). 
Duas outras entrevistadas, Cristiane e Mariana, também não participavam de nenhum projeto, mas disseram que gostariam de participar. As duas afirmaram que gostariam de fazer cursos de informática e inglês. Perguntei a elas se conheciam as aulas oferecidas por um "projeto social" que na época possuía um posto móvel para aulas de informática na praça que contorna a maioria das comunidades do complexo. O mesmo projeto contava também, segundo me havia dito sua coordenadora, com vagas abertas e ociosas para um curso de inglês. As jovens responderam:

Não, não conheço não. Nunca ouvi falar.

O curso de informática é lá na Praça Nóbel, num contêiner...

Nem sei onde é essa praça, é aqui perto?

É ali na descida da Caçapava.

Ih, eu não vou lá não, nunca fui lá não. É muito longe. (Cristiane, 16 anos, moradora do Morro do Andaraí).

Ah, eu já ouvi falar, é lá no Cemasi né?

[...] É eu ouvi falar. Eu ia até ver, mas não deu. (Mariana, 17 anos, moradora do Morro do Andaraí).

Roberto, um jovem que me foi apresentado por um dos gestores de um projeto na comunidade do Morro do Andaraí, também não participava de nenhuma atividade, embora frequentasse alguns eventos e festas promovidos por "projetos sociais". Foi em um desses eventos, um campeonato de judô, que o entrevistei. Roberto também falou da necessidade de existirem cursos no Andaraí, e que ele especificamente gostaria de fazer um curso de elétrica. Pareceu-me curioso o fato de a própria associação que organizava o evento em que estávamos oferecer um curso básico em elétrica. O professor era, inclusive, o gestor que havia me apresentado ao Roberto. Perguntei então se ele conhecia o projeto e o curso oferecido:

Se tivesse um curso de elétrica seria legal. Eu queria trabalhar na área de elétrica, eu acho muito maneiro...

Você sabe que aqui do lado, na igreja que tem aqui, tem um projeto e eles oferecem curso de elétrica...

Não, nem sabia... de repente depois eu passo lá. (Roberto, 20 anos, morador do Morro do Andaraí).

Os depoimentos acima evidenciam que há um planejamento dos jovens no que diz respeito ao seu futuro profissional. Yasmim e Kamila demonstram não apenas definições em relação à profissão que querem seguir, como também informações e planejamento sobre como pretendem alcançá-las. Kamila revela até uma alternativa (menos atraente) caso a carreira artística não "dê certo". Da mesma forma, Natânia destaca o fato de já obter a formação profissional na área em que pretende seguir profissionalmente. Cristiane disse que queria cursar faculdade de Direito ou Enfermagem. Mariana, que já concluía o Ensino Médio, prestaria em alguns meses vestibular para Engenharia. Segundo ela, deveria existir na região do Andaraí algum curso pré-vestibular para que os jovens pudessem frequentá-lo próximo de suas casas. Assim, pode-se perceber que a maioria dos jovens que entrevistei associam a participação em projetos com a formação ou qualificação profissional. A própria referência a cursos sempre que perguntados sobre projetos demonstra isso. Entretanto, é importante destacar que nem sempre os desejos pronunciados pelos jovens serão efetivados de forma imediata ou contínua. 
Apesar de tanto Yasmim quanto Kamila e Natânia afirmarem que gostavam muito de participar do projeto de dança, na época que as entrevistei o projeto se encontrava com as aulas suspensas, segundo elas mesmas, pela pouca assiduidade das alunas. Durante sua entrevista, Yasmim mencionou que tinha faltado a muitas apresentações do grupo. Quando perguntei o motivo, ela explicou que às vezes a mãe a proibia de ir às apresentações como castigo por algum comportamento. Outras vezes, era a professora que não a deixava participar já que ela não teria ido aos ensaios. Segue a sequência de sua fala:

Por que você não foi em muitas?

Algumas vezes eu estava de castigo e algumas vezes eu faltei à dança aí, eu não sabia a coreografia e ela não deixou eu participar.

E por quê que você falta? Quando você faltou essas vezes, foi por quêe?

Ah, não sei, às vezes eu chegava muito cansada da escola. A dança sempre começa sete horas e eu chego da escola sete horas, aí eu nunca levava a roupa na mochila e eu perdi a vontade de ir. Aí eu ficava faltando, faltando, faltando, faltando, aí ela não deixava.

Mesmo gostando das aulas de dança (ela me disse depois que a mãe quando a colocava de castigo proibia justamente a dança, por saber que ela gostava), Yasmim explica que faltou muitas vezes por estar cansada, ou por não ter levado a roupa na mochila, e que acabou perdendo a vontade de ir por um tempo. Em outro momento da entrevista, ela dizia que deveria haver mais projetos no Andaraí, especificamente alguns cursos. Quando perguntei a quais tipos de curso se referia, ela afirmou:

Ah, um curso de informática, não sei... de inglês e espanhol. Teve, mas eu não participei.

[...] Informática... de inglês... só.

Mas você não participou por quê?

Porque de inglês era sempre dia de sábado e dia de sábado eu nunca podia. E quando eu fui fazer as inscrições não tinha vaga mais.

A fala de Yasmim sobre o curso de inglês se assemelha às de Cristiane, Mariana e Roberto no que não demonstra, ao falar sobre a efetivação de sua participação no curso, o entusiasmo com o qual se referia à existência dos mesmos. Yasmim e Mariana explicaram de forma vaga o motivo de não terem participado de cursos nas temáticas que desejavam, apesar de confirmarem que sabiam de sua ocorrência. Da mesma forma, em relação a suas faltas no grupo de dança, Yasmim apresenta falas evasivas e motivos aparentemente casuais e inconclusivos. Apesar de a praça onde era oferecido o curso de informática ser constantemente mencionada e acessada por moradores de todas as comunidades do Complexo do Andaraí/Grajaú, Cristiane afirmou não ir nunca até ela e achá-la "muito longe". Roberto, após ser informado da existência de um curso de elétrica bem próximo a sua residência, demonstrou dúvida em relação a procurá-lo. O depoimento de outra entrevistada, Fabiana, se desenvolveu de forma semelhante embora se destaque por uma presumível maior distância entre o que ela define como objetivo profissional e as atividades que desenvolvia no momento. Logo no início da entrevista, Fabiana contou que tinha deixado de ir à escola ainda no Ensino Fundamental. Desde então, não estudava mais. Disse também que nunca tinha trabalhado. Não participava de nenhum projeto. Quanto a seus objetivos profissionais, afirmou:

Eu quero ser médica, eu acho muito legal.

Mas você sabe que para ser médica você precisaria voltar a estudar...

Eu sei, talvez no ano que vem eu volte. É que é muito chato. (Fabiana, 17 anos, moradora da comunidade Juscelino Kubitschek). 
Apesar de eleger uma profissão que requer um amplo preparo acadêmico, Fabiana demonstra dúvida sobre quando voltará a estudar. A explicação para tal dúvida também é sucinta e se refere a uma percepção individual de Fabiana, não fazendo referência direta às contingências socioeconômicas ou outras características estruturais que poderiam ser presumidas como motivo para a evasão escolar.

A fala dos meus entrevistados assemelham-se muito às encontradas por João Trajano Sento-Sé e Maria Claudia Coelho (2011) ao entrevistarem alguns jovens sobre os motivos de terem deixado o sistema de ensino formal. Alguns dos entrevistados apresentaram como razão para não frequentarem mais a escola a "preguiça", "enjoo" e até o "sol" (quente), embora muitos tenham dito planejar retornar aos estudos no futuro. Segundo os autores:

Instados a explicar o porquê de suas ações, oferecem explicações em que as motivações soam vagas ou mesmo inexistentes. Não se trata, evidentemente, de dizer que os entrevistados não tiveram motivações para agir do modo como fizeram, mas sim que suas atitudes são percebidas por eles e descritas como ocorrendo ao sabor das circunstâncias, sem que haja reflexões e decisões que antecipem a ação. É uma forma de compreensão das relações de causalidade de seus atos marcada pela casualidade: uma causalidade casual. (SENTO-SÉ; COELHO, 2011, p. 38).

Torna-se evidente que por mais que os jovens possam ter planos biográficos elaborados isso não significa que irão cumpri-lo da forma como um observador poderia esperar. Talvez a própria noção de planejamento do futuro, ou ao menos o início da efetivação de tais planos durante a juventude, seja de certa forma vaga para as juventudes atuais. Já expus a forma como diversos estudos sobre jovens de classes médias do Rio de Janeiro têm ressaltado a mobilidade experimentada por esses indivíduos nos diversos âmbitos de suas vidas sociais. Nas formas de lazer noturno, nos relacionamentos afetivos e na construção de carreiras profissionais, por exemplo, pode ser observada uma transitoriedade constante que proporciona múltiplas formas de identificação e gera trajetórias biográficas descontínuas e fluidas. Segundo Gilberto Velho (1987), a volatilidade desses percursos jovens seria causada pela grande oferta de escolhas disponíveis na vida moderna em sociedades complexas. $\mathrm{O}$ autor ressalta que por sociedade complexa compreende aquelas que seriam frutos da Revolução Industrial, caracterizadas por uma ampla divisão social do trabalho. Abrangeriam ainda uma heterogeneidade cultural, definida como "a coexistência, harmoniosa ou não, de uma pluralidade de tradições cujas bases podem ser ocupacionais, étnicas, religiosas e etc." (VELHO, 1987, p. 14). Perante as inúmeras possibilidades de escolhas existentes nos mais variados âmbitos da vida moderna, os indivíduos construiriam suas trajetórias visando se perceber como unidade, diferenciar-se, buscando "dar um sentido ou uma coerência a essa experiência fragmentadora" (VELHO, 1987, p. 34). É nesse contexto que se inserem as análises sobre os jovens de classes médias, ou seja, suas identidades fluidas, compostas por momentos transitórios de identificação, estariam de acordo com seus projetos também voláteis, construídos em adequação ao mundo moderno.

O mesmo, entretanto, não pode ser observado em relação às análises sobre as construções de trajetórias dos jovens de classes populares. Enquanto a percepção sobre a juventude de classe média ratifica suas múltiplas trajetórias, no caso dos jovens moradores de favelas ressalta-se normalmente a força das determinações sociais sobre suas "frágeis" identidades. Trata-se aqui de uma oposição clássica entre autonomia individual e determinação sociocultural, que pode ser resumida na perspectiva das "escolhas". Não se presume que os jovens de classes médias não sejam influenciados pelos contextos nos quais se inserem e nem que os jovens favelados não construam biografias individualizadas de alguma forma; o que se coloca é a ênfase nas escolhas de uns e a subestimação das escolhas dos outros. Enquanto a principal característica atribuída à juventude de classes médias é a mobilidade, feita por suas escolhas, à juventude favelada é atribuída uma vulnerabilidade, gerada pelo meio onde vivem.

Alguns autores que estudam as trajetórias juvenis em classes populares já têm destacado, porém, que algumas das "razões" normalmente acionadas para explicar o contexto de vulnerabilidade dos jovens precisam ser relativizadas. Segundo Sento-Sé e Coelho: 
São tão volumosas as pesquisas que associam a fragmentação familiar, o fracasso escolar e as baixas perspectivas de futuro a comportamentos criminais reiterados, que tais variáveis se tornaram uma espécie de paradigma para a análise do crime como fenômeno social. [...] Os três elementos tratados aqui como quase-paradigmas têm, como foi dito, se revelado bastante consistentes, mas não exatamente conclusivos, como quase tudo em criminologia, na explicação de comportamentos criminais. Isso porque se referem a três aspectos da vida social - a família, a escola e a temporalidade - que estão sofrendo, reconhecidamente, um processo de redefinição semelhante àquele que os clássicos da sociologia elencaram como temas privilegiados de suas análises em suas respectivas contemporaneidades (a vida religiosa, o mundo do trabalho, o parentesco, as relações econômicas, a administração, para ficar nos exemplos mais óbvios). A transformação de paradigmas explicativos em dados naturalizados de certas dinâmicas sociais é um risco contra o qual se deve adotar o salutar exercício da dúvida e da problematização, sobretudo quando estamos lidando com um campo como a criminologia, cujo caráter aplicado e orientador de políticas é tão decisivo. (2011, p. 3).

Observa-se que as próprias configurações modernas de família, de escola e de perspectivas de futuro seriam imprecisas e não poderiam servir de explicação única ou naturalizada para uma vida de vulnerabilidade social. Do mesmo modo, após entrevistarem jovens de classes populares com diferentes trajetórias individuais, os autores perceberam que os envolvimentos com a criminalidade ocorriam, muitas das vezes, de formas ocasionais, não constituindo uma "carreira" criminosa propriamente dita. As fronteiras entre o "estar" e o "não estar" no mundo do crime não seriam, para esses jovens, tão definidas como para outros segmentos da sociedade. Pelo contrário, às vezes eles tratariam como brincadeiras e trivialidades cenas que aos olhos de outros consistiriam em casos explícitos de violência e "bandidagem". De acordo com os autores: "Brincadeira, traquinagem, transgressão, crime: estas categorias parecem consistir em um continuum de fronteiras difusas, em que o personagem pode facilmente escorregar de um termo a outro, muitas vezes para sua própria surpresa...” (2011, p. 29).

Sílvia Ramos também fala sobre os motivos de envolvimento com o crime, apontados pelos jovens abordados em sua pesquisa:

Nossas páginas de material bruto reuniram um repertório considerável de registros em que o jovem não precisava de dinheiro ('ele tinha tudo'), não vinha de família desestruturada (tinha casa, mãe, irmãos, estava na escola), não estava deslocado de seu grupo de amigos (pelo contrário, era integrado, querido, enturmado), não estava 'ocioso' (além da escola, ele fazia parte de 'projetos' na favela). Em muitos casos adolescentes declaram que vão para o tráfico em busca de dinheiro, alternativa profissional, para fugir de famílias violentas, para escapar de pais ou mães alcoolizados e violentos, ou por outros motivos socioeconômicos 'clássicos'. Mas é importante perceber que em tantos outros casos as trajetórias de vida não correspondem às razões tidas como mais óbvias, e que de alguma maneira esperamos que nossos interlocutores reiterem. (2011, p. 49).

A autora afirma, assim, que as trajetórias dos jovens no tráfico organizado são incertas. O envolvimento contém ao mesmo tempo elementos de repulsa e fascínio. Dessa forma, os vínculos se configuram de forma instável, descontínua, alternando momentos dentro e fora da criminalidade. Ela afirma que:

Ouvimos jovens que entraram e saíram do tráfico para nos aproximar da compreensão sobre por que alguns jovens traçam seus percursos de vida no mundo das armas, do crime, das drogas. Quando o tráfico já não dá tanto dinheiro, é incerto, arriscado, paga mal, é cansativo e impõe jornadas e encargos de trabalho que se não forem cumpridos podem custar a vida e ainda é um mundo cheio de 'vaidades' e 'falsidades', é difícil construir discursos sobre as razões para entrar. Como veremos, o discurso sobre quem entrou e saiu é sempre uma 
construção crítica sobre o erro, a bobeira, a vacilação. Mas não encontramos exatamente arrependimento. Talvez alívio, por ter saído a tempo e vivo. Alguns entrevistados mencionaram que mesmo quando um jovem já saiu do tráfico, quando ele fala do passado, 'chega o olho brilha. Tem um prazer ali'. De fato, observamos claramente esse fenômeno em vários momentos da pesquisa. (RAMOS, 2011, p. 53).

Assim, pode-se perceber que não apenas o envolvimento com o tráfico pode ocorrer em variados contextos, por impulsos ou condições de vida, mas ele também se dá de maneira fluida, volátil, onde períodos de participação podem alternar-se com períodos de trabalho formal, por exemplo. De acordo com Sento-Sé e Coelho (2011), também em outras áreas das vidas dos jovens de camadas populares podem ser encontradas trajetórias descontínuas:

Errâncias, imprecisões, ambivalências: estes termos parecem dar a tônica daquilo que os jovens entrevistados contam sobre suas trajetórias. Perguntados sobre suas trajetórias familiares, falam de famílias múltiplas, eventualmente co-existentes no tempo; contam sobre vivências 'nômades', sem habitação fixa; revelam um sentimento em que o responsabilizar-se não é função de um papel socialmente definido, mas parece se dar (quando se dá) de forma aleatória, ditada não por critérios macro-sociológicos de organização social, mas, ao menos em sua percepção, ao sabor dos desejos e personalidades individuais. (SENTO-SÉ; COELHO, 2011, p. 28).

As reflexões acima revelam que as trajetórias jovens em classes populares, assim como em classes médias, podem ser caracterizadas por inúmeros momentos, causalidades e até incoerências. Suas identidades se formariam também através de instantes biográficos transitórios, não podendo ser compreendidas através de padronizações simplistas ou estereótipos. O envolvimento com crime, as configurações familiares e de moradia tradicionais e a evasão escolar configurariam uma das possibilidades de conduta entre várias possíveis também a esses jovens. Segundo Gilberto Velho, a existência e legitimidade de projetos individuais estaria "vinculada a como, em contextos sócio-culturais específicos, se lida com a ambiguidade fragmentação-totalização" (1987, p. 27). Dessa forma, o autor questiona até que ponto, nas classes populares, seriam valorizadas as perspectivas de direcionamento das biografias em relação a fins longínquos definidos, visto a força das conjunturas sociais no meio onde vivem. Sento-Sé e Coelho (2011) observaram que na pesquisa com jovens afastados de qualquer institucionalização, as trajetórias individuais se mostravam mesmo completamente vagas, apontando uma falta de orientação das condutas presentes em relação ao futuro. De acordo com os autores:

Estes projetos, contudo, são regidos pela imprecisão e, em particular, pela aparente inexistência de um vínculo de causalidade entre presente e futuro, uma vez que as atitudes e escolhas do momento presente não parecem guardar relação com a concretização de seus projetos para o que está por vir. É assim que vemos um projeto, tal como ser advogada, formulado por uma moça que está fora da escola no momento da entrevista, ou projetos profissionais de naturezas muito díspares aparecerem como opções no mesmo depoimento (telemarketing e enfermagem, motorista de ônibus e comerciante). (SENTO-SÉ; COELHO, 2011, p. 20).

A incoerência e descontinuidades observadas nas trajetórias juvenis em relação ao que dizem ser seus planos futuros (que fazem os autores sugerirem uma indistinção entre planos e sonhos) podem confirmar a ideia de que no universo desses indivíduos os projetos individuais não seriam tão valorizados ou legitimados. A questão que se coloca é até que ponto essas incertezas são distintas daquelas que possivelmente seriam encontradas em narrativas de jovens de classes médias. Afinal, os mesmos jovens que apresentam de forma vaga, quase inexistente, seus projetos para o futuro, constroem percursos voláteis em relação ao tráfico organizado, em relação à escola, em relação aos 
contextos familiares, entre outros. Oferecem como explicações para essas transitoriedades, muitas vezes, características individuais, ocasionais, que não passam necessariamente pelo contexto de vulnerabilidade no qual viveriam. A operacionalização de escolhas se torna evidente.

\section{Considerações finais}

O objetivo deste trabalho não é, de forma alguma, uma tentativa de medir ou mesmo comparar o conjunto de possibilidades que se apresentam aos jovens de diferentes classes sociais e nem ignorar os diferentes níveis de legitimação e importância que os projetos individuais possuem entre eles. As inúmeras dificuldades impostas aos moradores de periferias, especialmente favelas, pelo descaso governamental e pela opressão capitalista são inquestionáveis. O que não parece mais concebível na discussão sobre jovens de classes populares é a desconsideração de suas escolhas individuais, de suas trajetórias múltiplas, por mais restritos que sejam seus "campos de possibilidades". Se algum dia a vida social nas favelas já foi desenvolvida predominantemente através de padronizações e generalizações oriundas das contingências socioeconômicas, o contexto vivenciado hoje possibilita de forma clara a diferenciação de si, a afirmação individual. Talvez esse seja um resultado da difusão tecnológica que globalizou o acesso a informações diversas, levando com elas modos de vida e perspectivas individualistas. Talvez seja já fruto da ação das políticas e projetos sociais dedicados a oferecer nas favelas projetos de vida mais semelhantes aos desenvolvidos nas classes médias. Algumas pesquisas (PAIS, 2006; RAMOS, 2006; SENTO-SÉ e COELHO, 2011) demonstram que a participação em "projetos sociais" pode gerar incentivos à afirmação individual, à perspectiva protagonística. De qualquer forma, Gilberto Velho já indicou que o estudo de grupos de uma mesma sociedade, como por exemplo os diferenciados por classes sociais, deve ter cuidado ao presumir as diferenças fundamentais entre eles. O perigo seria isolar grupos que, por mais divergentes que possam ser em suas formas de vida, compartilhariam códigos e mecanismos sociais. Ele diz: "Uma questão interessante em antropologia é, justamente, a procura de localizar experiências suficientemente significativas para criar fronteiras simbólicas" (1987, p. 15). O isolamento dos jovens pobres tem há anos incitado a sua classificação como potencialmente perigosos, passíveis de desconfiança e suspeição. As consequências desse estigmamento contínuo são vistas diariamente nos números da violência sofrida por esses jovens, que configuram, segundo Sílvia Ramos (2009), a "idade da morte", a "cor da morte" e a "geografia da morte" no Rio de Janeiro. Suas transitoriedades, indecisões e ambivalências tendem a ser vistas como um problema social, um risco eminente de envolvimento com o crime, apesar de serem observadas de forma muito semelhante entre os jovens de camadas médias, nos quais são normalizadas e aceitas.

\section{Referências}

ALMEIDA, Maria Isabel. Criatividade contemporânea e os redesenhos das relações entre autor e obra: a exaustão do rompante criador. In: ALMEIDA, Maria Isabel; PAIS, José Machado (org.). Criatividade, juventudes e novos horizontes profissionais. Rio de Janeiro: Zahar, 2012. p. 21-55.

ALMEIDA, Maria Isabel; EUGÊNIO, Fernanda (org.). Culturas jovens. Rio de Janeiro: Zahar, 2006.

ALMEIDA, Maria Isabel; PAIS, José Machado (org.). Criatividade, juventudes e novos horizontes profissionais. Rio de Janeiro: Zahar, 2012.

ALMEIDA, Maria Isabel; TRACY, Kátia. Noites nômades. Rio de Janeiro: Rocco, 2003. 
BECKER, Howard. Art Worlds. Berkeley: University of California Press, 1982.

CARDOSO, Adalberto. Transições da escola para o trabalho no Brasil: persistência da desigualdade e frustração de expectativas. Revista de Ciências Sociais, Rio de Janeiro, v. 51, n. 3, p. 569-616, 2008.

EUGÊNIO, Fernanda. Corpos voláteis: afeto e consumo na "cena carioca”. In: ALMEIDA, Maria Isabel; EUGÊNIO, Fernanda (org.). Culturas jovens. Rio de Janeiro: Zahar, 2006. p. 158-176.

EUGÊNIO, Fernanda. Criatividade situada, funcionamento consequente e orquestração do tempo nas práticas profissionais contemporâneas. In: ALMEIDA, Maria Isabel; PAIS, José Machado (org.). Criatividade, juventudes e novos horizontes profissionais. Rio de Janeiro: Zahar, 2012. p. 210-258.

FERNANDES, Raquel Brum. Vítimas ou autores? Percepções sobre a juventude e o tráfico em um conjunto de favelas “pacificadas" no Rio de Janeiro. Interseções, Rio de Janeiro, v. 15 n. 2, p. 374-391, dez. 2013.

NOVAES, Regina. Os jovens de hoje: contextos, diferenças e trajetórias. In: ALMEIDA, Maria Isabel; EUGÊNIO, Fernanda (org.). Culturas jovens. Rio de Janeiro: Zahar, 2006. p. 105-120.

PAIS, José Machado. Buscas de si: expressividades e identidades juvenis. In: ALMEIDA, Maria Isabel; EUGÊNIO, Fernanda (org.). Culturas jovens. Rio de Janeiro: Zahar, 2006. p. 7-21.

PICCOLO, Fernanda. Desigualdades sociais, práticas educativas e juventude numa favela carioca. In: VELHO, Gilberto; DUARTE, Luis Fernando (org.). Juventude contemporânea. Rio de Janeiro: 7 Letras, 2010. p. 110-128.

RAMOS, Silvia. Brazilian responses to violence and new forms of mediation: the case of the Grupo Cultural AfroReggae and the experience of the project "Youth and the Police". Ciência e Saúde Coletiva, Rio de Janeiro, v. 11, n. 2, p. 419-428, 2006.

RAMOS, Silvia. Meninos do Rio: violência armada e polícia nas favelas cariocas. Boletim do Cesec, Rio de Janeiro, $\mathrm{n}$. 13, ano 8, 2009.

RAMOS, Silvia. Trajetórias no tráfico: jovens e violência armada em favelas cariocas. Revista Eletrônica Trivium, Rio de Janeiro, v. 3, n. 2, p. 41-57, 2011. Disponível em: https:/www.ucamcesec.com.br/wp-content/uploads/2012/03/ trajetorias-do-trafico-jovens-e-violencia-armada-em-favelas-cariocas.pdf. Acesso em: 5 jun. 2013.

REZENDE, Claudia. Diversidade e identidade: discutindo jovens de camadas médias urbanas. In: VELHO, Gilberto (org.). Individualismo e juventude. Rio de Janeiro: Museu Nacional - UFRJ, 1990. n. 18, p. 5-24.

ROCHA, Everardo; ALMEIDA, Maria Isabel; EUGÊNIO, Fernanda (org.). Comunicação, consumo e espaço urbano: novas sensibilidades nas culturas jovens. Rio de Janeiro: PUC-Rio/Mauad, 2006.

SENTO-SÉ, João Trajano; COELHO, Maria Claudia. Sobre errâncias, imprecisões e ambivalências: notas sobre as trajetórias de jovens cariocas e sua relação com o mundo do crime. Horizontes Antropológicos, Porto Alegre, v. 20, n. 42 , p. 327-357, 2014

VELHO, Gilberto. Individualismo e cultura: notas para uma Antropologia da sociedade contemporânea. Rio de Janeiro: Zahar, 1987.

VELHO, Gilberto. Introdução. In: VELHO, Gilberto (org.). Individualismo e juventude. Rio de Janeiro, Museu Nacional - UFRJ, 1990. n. 18, p. 1-3.

VIANNA, Hermano (org.). Galeras cariocas: territórios de conflitos e encontros culturais. Rio de Janeiro: Editora da UFRJ, 1997.

Data de submissão: 31/01/2021

Data de aceite: 18/02/2021 